\title{
Living Without OTAs-Goodbye Columbus: Putting the Jenie Back in the Bottle
}

Cornell Hospitality Quarterly

2018, Vol. 59(I) 67-69

(C) The Author(s) 2017

Reprints and permissions:

sagepub.com/journalsPermissions.nav DOI: $10.1177 / 1938965517735907$

journals.sagepub.com/home/cqx

QSAGE

\author{
Chris K. Anderson' and Saram Han'
}

\begin{abstract}
A recent Cornell Hospitality Quarterly article highlighted a unique natural experiment where an entire city had all its hotel delisted from all online travel agents for more than 4 years. The article provides great background to the delisting and highlights the impacts on hotel revenue and accommodation taxes for the county. The article estimates that even though the hotels relisted at all online travel agents (OTAs), there was a substantial gain to both hotels and accommodation tax collectors during the OTA delisting period. The impact estimates are based solely on the loss of demand realized in neighboring Phenix City, AL, once Columbus is relisted at OTAs. In the following, we highlight some concerns with these estimates and indicate that the losses may in fact be quite substantive and perhaps more indicative of why Columbus hotels relisted at the OTAs.
\end{abstract}

\section{Keywords}

distribution; marketing and sales; revenue management; operations; hotel management; operations

\section{Estimates of Impacts to Columbus}

McLeod, Litvi, Heriot, Jauregui, and Dempsey (2017) estimate the impact of OTA delisting by looking primarily at demand changes in Phenix City, AL (across the river and state line from Columbus). They estimate that once Columbus was relisted at the OTAs, Phenix City lost about 18,000 rooms nights per year and used this loss post relisting as the loss (gain to Phenix City) during the delisting phase of Columbus. They then estimate a tax gain to the city of Columbus of US $\$ 298,000$ which is composed of a small loss of taxes on the 18,000 room nights per year (over 4.3 years of delisting) which is offset by higher net taxable rates owing to a loss of OTA transactions (assuming 14.9\% of transactions taxed at a lower net rate owing to the $20 \%$ estimated OTA commissions).

Similarly, they estimate impacts upon hotels in Columbus through the loss of 18,000 annual room nights over the delisting period at US\$5,542,000 (18k [annual lost rooms] $\times$ 4.3 [years delisted] $\times$ US $\$ 71.60$ [average delisting period Columbus average daily rate (ADR)]). But this substantive loss is offset by reductions in OTA commission of US\$9,257,000 $(1,009 \mathrm{k}$ [annual average number of room nights sold in the city during delisting] $\times 4.3$ [years delisted] $\times$ US\$71.60 [average delisting period Columbus ADR] $\times 14.9 \%$ [OTA normal market share] $\times 20 \%$ [average OTA markup]) for a net gain of US\$3,715,000.

The result of putting the OTA Jenie back in the bottle in Columbus appears quite positive — so much so one might ask why the hotels bothered to relist!
McLeod et al. (2017) indicate that only 18,000 of the estimated 150,341 (14.9\% of 1,009k) annual rooms sold on OTAs prior to delisting were lost to other markets based on room demand changes in Phenix City. It should be noted that while Phenix City is the next closet market, it only has one seventh of the room supply as Columbus (246k vs. $1,720 \mathrm{k}$ rooms as of 2014), and perhaps this supply imbalance might mean room nights are lost to other markets as well. They also assume that OTA delisting has no long-term impacts on pricing strategy within the Columbus market as revenue estimates are solely based on ADRs during the delisted period.

\section{Alternative Estimates}

While the delisting of hotels in Columbus, with Phenix City a stone's throw across the river, is being a natural experiment in OTA impacts, it is still very difficult to unravel the true impacts of OTA delisting owing to a lot of other factors not within control of the experiment. As discussed by McLeod et al. (2017), changes in market supply coupled with changes in demand make it difficult to ascertain impacts. One of the simplest methods to control for demand and supply changes is to evaluate impacts using indices

'Cornell University, Ithaca, NY, USA

Corresponding Author:

Chris K. Anderson, Cornell University, Ithaca, NY I4853, USA

Email: cka9@cornell.edu 


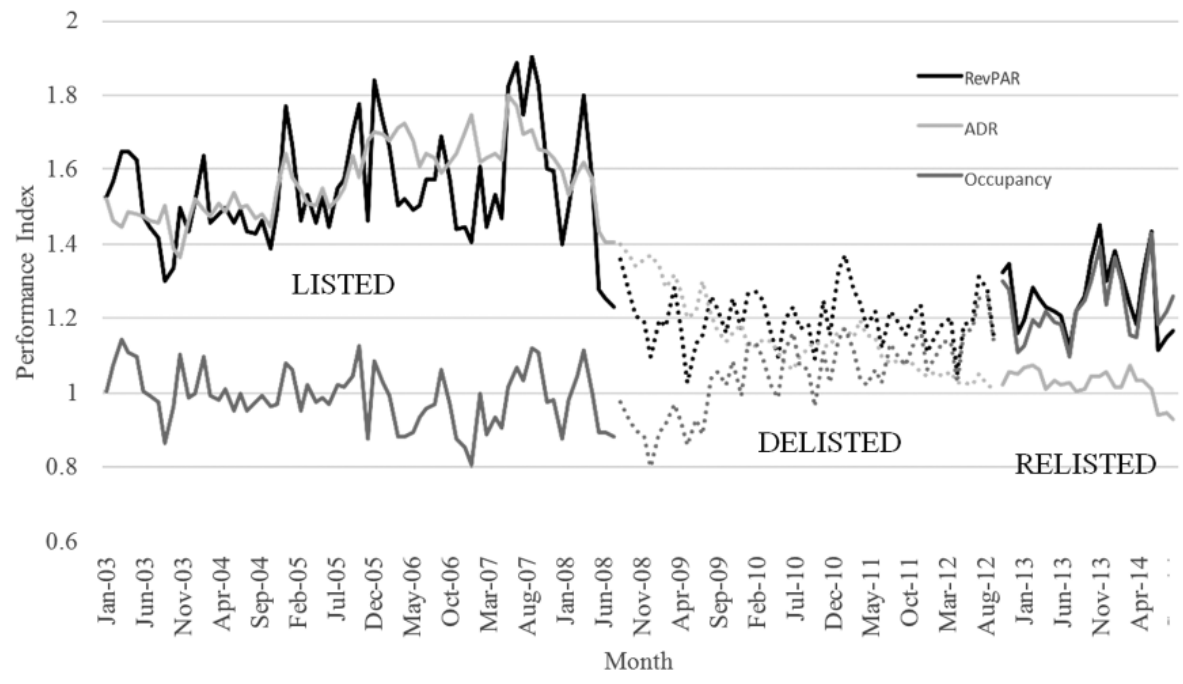

Figure 1.

Hotel Performance Indices (Columbus/Phenix City).

versus absolute values - so instead of focusing on ADRs in Columbus, focus on ADRs in Columbus relative to those in Phenix City.

Figure 1 displays RevPAR, ADR, and Occupancy before, during, and after OTA delisting in Columbus. ${ }^{1}$ To control for seasonality and the underlying changes in overall demand, the figure presents these metrics as indices - that is, RevPAR is RevPAR in Columbus/RevPAR in Phenix City. The figure illustrates that prior to delisting, Columbus generated a rate premium over Phenix City which translated into superior RevPAR performance-although this rate premium was readjusting in 2008 owing to the recession. Following delisting, Columbus rates eroded very quickly; these rate reductions generated modest occupancy gains, but resulted in dramatically reduced overall performance as measured by RevPAR. Following relisting, Columbus never recovered its pricing power as ADRs continued to depreciate (relative to Phenix City) but relisting generated sufficient demand to elevate RevPAR (but not to predelisting levels).

Table 1 summarizes average performance indices during the three periods and calculates ratios of the Delisted (Loss) and Relisted (Recovery) periods relative to performance prior to delisting. The ratios further highlight the degree to which Columbus hotels lost control of their pricing actions and failed to recover even after relisting (relative to Phenix City) as relisted prices are 35\% less than those prior to delisting.

Table 1 and Figure 1 would indicate that Columbus hotels faired very poorly during delisting losing considerably more (on a relative basis) to the estimated 18,000 annual room nights - in fact one might argue they lost very few if any room nights (as occupancy indices increased).
Table 1.

Hotel Performance Indices (Columbus/Phenix City).

\begin{tabular}{lccc}
\hline & RevPAR & ADR & Occupancy \\
\hline Listed & 1.54 & 1.57 & 0.99 \\
Delisted & 1.20 & 1.15 & 1.05 \\
Relisted & 1.26 & 1.02 & 1.23 \\
Loss & $77.6 \%$ & $73.5 \%$ & $106.2 \%$ \\
Recovery & $81.4 \%$ & $65.2 \%$ & $124.8 \%$ \\
\hline
\end{tabular}

Note. RevPAR = revenue per available room; $A D R=$ average daily room rate.

However, Columbus hotels aggressively reduced prices resulting in RevPAR (i.e., total revenue) dramatically decreasing. One thing to keep in mind is that revenues reported to Smith Travel Research (STR) are net revenues (net of all OTA commissions), so the RevPAR indices during the listed and delisted periods already have all OTA commission savings built in-so there is no need to make any assumptions on channel mix or commissions as required in McLeod et al. (2017). But looking at Columbus/Phenix City indices may not be a very realistic measure of impact as it is most likely double counting the impact as some of the losses from Columbus become the gains to Phenix City. We can conservatively adjust for double counting through adjustment of the indices using the average performance across both markets in the denominator, that is,

$$
\frac{\text { Columbus }}{(\text { Columbus }+ \text { Phenix City }) / 2} \text {. }
$$

We summarize these revised indices in Table 2. 
Table 2.

Adjusted Hotel Performance Indices.

\begin{tabular}{lccc}
\hline & RevPAR & ADR & Occupancy \\
\hline Listed & 1.21 & 1.22 & 0.99 \\
Delisted & 1.09 & 1.07 & 1.02 \\
Relisted & 1.11 & 1.01 & 1.10 \\
Loss & $89.9 \%$ & $87.6 \%$ & $102.9 \%$ \\
Recovery & $91.8 \%$ & $82.9 \%$ & $111.1 \%$ \\
\hline
\end{tabular}

Note. RevPAR $=$ revenue per available room; $A D R=$ average daily room rate.

Table 2 shows that after adjusting for double counting, RevPAR losses during delisting were a little more than $10 \%$ with only $2 \%$ of these losses recovered upon relisting with these losses stemming from dramatically reduced prices in Columbus (relative to Phenix City).

One last minor comment on accommodation tax impacts. In McLeod et al. (2017), they assume that during delisting, incremental taxes would be recovered on all OTA bookings (assuming they moved to other channels); this assumption fails to incorporate the fact that the entire tax issue focused on Merchant OTA bookings (transactions where the OTA was the merchant of record with taxes recovered on net rates to OTAs - rate minus commission). All OTA bookings made at Booking.com and some at Priceline.com (after 2011) and Expedia.com (during 2012) are executed in the so-called Retail model where the hotel is the merchant of record, and as a result, accommodation taxes are paid on the full retail selling price (not net price as in the Merchant model). The retail or pay when you stay in OTA model does not require consumers to pay in advance as they simply pay at departure like most hotel reservations, and thus, accommodation taxes are on the full room rate with the hotel remitting commissions to the OTA after the stay. The merchant model has the OTA "paying" the hotel the net rate and OTAs argued that this was the actual rate paid to the hotel and as such should be the rate accommodation taxes are based on. As a result of this change in transaction mode, some (not all) of the tax savings would have been recognized even if Columbus had remained listed at OTAs.

The goal of this note is not to put a firm number of the impacts of delisting as done in McLeod et al. (2017) but rather highlight the implications of the assumptions they made. We illustrate an alternative view of the impacts of delisting, one which controls demand and supply changes through use of indices versus use of absolute demand numbers. We further highlight that McLeod et al. (2017) assume all demand lost from Columbus spilled over to Phenix City which seems very aggressive as Columbus hotels displayed for OTA searches performed for numerous nearby markets not just Phenix City.

\section{Declaration of Conflicting Interests}

The author(s) declared no potential conflicts of interest with respect to the research, authorship, or publication of this article.

\section{Funding}

The author(s) received no financial support for the research, authorship, or publication of this article.

\section{Note}

1. Data used are same as used in McLeod et al. (2017) as supplied by Smith Travel Research (STR) under an educational agreement known as the STR SHARE Center.

\section{Reference}

McLeod, B., Litvin, S. W., Heriot, K. C., Jauregui, A., \& Dempsey, E. (2017). Goodbye Columbus: Accommodation Taxes and OTAs. Cornell Hospitality Quarterly. Advance online publication. doi:10.1177/1938965517704369

\section{Author Biographies}

Chris K. Anderson is a Professor at Cornell University's School of Hotel Administration, SC Johnson College of Business and Director of Cornell's Center for Hospitality Research. He teaches and conducts research in data analytics, pricing, distribution and revenue management.

Saram Han is a PhD student in Marketing at the Cornell School of Hotel Administration in the Cornell SC Johnson College of Business. His research Interests include data science, natural language processing for OTAs review, service operation, service marketing, and survey methodology. He earned a Bachelor of Business Administration, Tourism Management, from Kyung-Hee University, Seoul, Korea, and an MS degree from the Michigan Program in Survey Methodology, University of Michigan. 